\title{
INTEGRAL ESTIMATION OF ACTIVITY OF ENTREPRENEURIAL UNIVERSITIES: PRACTICAL ASPECT
}

\author{
Gulshan Bayramoval \\ ${ }^{1}$ University and Enterprise Center, Baku Business University, Baku, Azerbaijan \\ E-mail: valvda@meta.ua \\ ORCID: https://orcid.org/0000-0003-0446-2600
}

A R T I L E IN F O
Article history:
Received date 23.11 .2021
Accepted date 22.12 .2021
Published date 30.12 .2021
Section:
Educational Policy \& Reform
D O I
10.21303/2313-8416.2021.002190
K E Y W O R D S
entrepreneurial university
integrated indicator
ranking
educational institutions
global development

ABSTRACT

Investigated problem. Implementation of the concept of an entrepreneurial university necessitates the formation of a system of activity indicators of educational institutions.

The main scientific results. It is specified that the activity of entrepreneurial universities and educational institutions that try to comply with this concept should be systematically rated. The author analyzes modern approaches to estimation of the activity of entrepreneurial universities. The own viewpoint to this evaluation on the basis of calculation of an integrated indicator is offered. The main stages of the algorithm for estimating the activity are described. An integrated activity indicator for five universities has been calculated. The ranking of educational institutions in accordance with the calculated desegregated measures and the concept of entrepreneurial university has been held. The results of the analysis showed that the studied educational institutions from the United States are more in line with the concept of the entrepreneurial university than European ones.

The area of practical use of the research results. The practical results of the study can be used in the process of estimating the activity of entrepreneurial universities.

Innovative technological product. The scientific approach to the evaluation of the activity of entrepreneurial universities proposed by the author allows to form their rating, to track the position of each educational institution in the dynamics.

Scope of application of the innovative technological product: educational policy at the micro- and macroeconomic levels.

(C) The Author(s) 2021. This is an open access article under the Creative Commons CC BY license

\section{Introduction}

Innovations in education are an important condition for its improvement and development. It is from these positions that it is expedient to consider the concept of the entrepreneurial university. With the implementation of the paradigm of lifelong learning, the educational institution begins to implement functions that are associated not only with learning, but also, more importantly, with regional and global development, solving social problems. The activities of entrepreneurial universities and educational institutions that try to comply with this concept should be systematically evaluated. This is important to improve activity given the need for self-improvement. That is why the issue of estimating the activity of entrepreneurial universities is important and relevant.

\section{1. The object of research}

The object of research is the activity of entrepreneurial universities.

\section{2. Problem description}

The study of different attitudes to understanding the paradigm of the entrepreneurial university is considered in the book [1]. The authors substantiate the thesis that the interaction between the university and industry can have a positive impact on the amount of money raised to fund research. It is noted that the activity of universities should be socially and economically significant [1].

The article by the team of authors [2] is devoted to the problems of outlining the list of indicators that characterize entrepreneurial universities in the global rankings of educational institutions. The team of authors [2] points to the change in the nature, goals and ways of functioning of modern educational institutions. The authors emphasize that the transformation of knowledge and scientific discoveries into social and economic development (the so-called third mission) are becoming part of the activity of educational institutions. Indicators that characterize the activity 
of the educational institution in the third mission should take into account not only the educational and research component. In the article, the authors analyze eight world rankings from the standpoint of the characteristics of the entrepreneurial university. The results of the authors' study [2] indicate that these indicators are insufficiently represented in the rankings. The article proposes [2] a system of indicators, which, according to the authors, more fully present the activity of entrepreneurial universities.

The article by the team of authors [3] is devoted to the study of the impact of the entrepreneurial university (teaching, research, etc.) on the entrepreneurial economy. The article notes that in the entrepreneurial economy the dominant factor of production is the capital of knowledge, which is a source of competitive advantage. It interacts with entrepreneurial capital, which provides the ability to engage in and generate entrepreneurial activity. The authors proposed a conceptual model that was tested using data from 147 universities located in 74 regions of the United Kingdom collected during 2005-2007. The results of the analysis [3] show a positive economic impact of educational, scientific and entrepreneurial activities.

Issues of formation of entrepreneurial universities in Azerbaijan are considered in the article [4]. The factual basis of the study was the data of five world rankings of universities. It is substantiated that the formation of entrepreneurial universities in Azerbaijan will have a positive impact on the socio-economic development of the country and increase the ranking of educational institutions. The author [4] emphasizes the need to study and summarize the best foreign experience in the operation of entrepreneurial universities.

The issue of formation of organizational and economic mechanism of regulation of the higher education system is considered in the article [5]. The authors propose a set of measures aimed at improving the efficiency of the education system.

The article [6] notes that the concept of the entrepreneurial university is now recognized as a major driver of self-development and innovation. The authors describe the process of implementing this concept in three technological universities in Austria: TU Graz, TU Wien and MU Leoben. To this end, a review of existing programs, entrepreneurial initiatives and questionnaires was conducted. The authors [6] conclude that the entrepreneurial university model is the next stage in the development of education.

The aim of research is to summarize the existing scientific approaches to evaluating the activities of educational institutions based on the concept of an entrepreneurial university and substantiate their own concept.

\section{Materials and Methods}

The ranking method allowed to organize educational institutions on the basis of the calculated integrated indicator. The use of the method of comparative analysis allowed to compare the activities of universities as a whole and their individual characteristics, in accordance with the concept of the entrepreneurial university.

\section{Results and Discussion}

Further development of the concept of the entrepreneurial university requires the formation of directions and approaches to creating a system of estimation of their activities.

There are two main approaches to estimating the activity of universities: rating and combined.

Rating is the use of a rating system in evaluating the activity of universities. Nowadays, there are a large number of ratings, which are used to position universities depending on the chosen system of indicators. The most influential global rankings are: QS World University Rankings, Times Higher Education World University Rankings, Academic Ranking of World Universities, U-Multirank, Reurters 100. In addition to these ratings, there are a large number of national/regional ratings of universities. Each of the ratings has its own methodology for calculating the summary indicator, on the basis of which a particular university occupies the appropriate position in the rating. However, each of the above-mentioned ratings, taken separately, does not fully take into account the peculiarities of the concept of the entrepreneurial university. This is indicated, in particular [4].

The advantages of this approach are the ease of use of the rating results. The main disadvantage is the pre-defined, unchanged in a particular rating set of indicators on which the estimation is conducted. This set of indicators may be less informative about the entrepreneurial university. 
At the same time, there are regional ratings, which contain a system of indicators that allows to estimate the educational institution from the standpoint of the concept of the entrepreneurial university. These include, for example, the University Entrepreneurship Index [7]. The system of indicators of this rating includes [7]: Startup Activity, Job Creation, Investment, Universities Foster Alumni Entrepreneurship, University Commercialization and others. Unfortunately, this rating of universities is calculated based on educational institutions in Illinois (USA).

The second viewpoint is combined. The theoretical basis of this viewpoint is a reasonable choice of a system of indicators to estimate the activity of entrepreneurial educational institutions.

For example, the authors of the article [2] proposed six main characteristics of the given university: entrepreneurial orientation and thinking; knowledge transfer; value creation; interdisciplinarity; interaction and involvement; independence.

Consequently, the formation of a system of estimation indicators of this universities on the basis of these characteristics will allow the analysis of their activity.

According to [2], these indicators may indicate that universities are implementing innovative teaching and research methods, collaborating with business and developing creative concepts, methods and tools to solve social and industrial problems. Also, they are reflected in the use of know-how in business, organization and work with stakeholders [8, 9].

In turn, [10] believe that the model of the entrepreneurial university is revealed by the following features:

1. Formal factors: Entrepreneurial organizational and managerial structure, measures to support entrepreneurship, entrepreneurial education.

2. Informal factors: the attitude of the university community to entrepreneurship, entrepreneurial teaching methods, examples to follow and the reward system.

3. Resources: human, financial, physical and commercial capital.

4. Opportunities: status and prestige, networks and alliances, localization.

This is described in more detail [10] and by the team of authors [11].

According to the author, the combined approach is more promising because it allows to form a system of indicators, due to the hypothesis and objectives of the study.

The initial stage in the formation of a system of indicators is to determine the requirements for such a system, the identification of its main characteristics. The most significant are the following characteristics.

Complexity - the system of indicators should provide information that covers certain characteristics of the university.

Sufficiency - the number of indicators should be sufficient for the needs of the analysis of the entrepreneurial university.

Comparability - indicators should provide an opportunity to adequately compare the activity of two or more universities.

Adaptability - the system of indicators should provide the possibility of adaptation, changes in its composition given the dynamics of the external environment of the university.

In addition, it is advisable to agree with [12] that the system of indicators should be focused on the need to reconcile the interests of the university and society.

The author proposes to use a system of indicators for estimating the activity of entrepreneurial universities, which is based on a statistical and informative base of global ratings: Times Higher Education World University Ranking [13], Reuters Top 100 [14], U-Multirank [15].

Thus, when ranking universities according to the Times Higher Education World University Ranking, the following indicators are used [13]: Reputation, Staff to student ratio, Doctorate to student ratio, Doctorates awarded to staff ratio, Institutional income, International outlook, Research income, Research productivity, Citations, Industry income.

Each of the indicators has a different weight in the overall measures, given their importance and role in the functioning of the university.

The U-Multirank rating consists of the following generalizing indicators [15]: General, Teaching and learning, International orientation, Research, Knowledge transfer, Regional engagement.

Each of the common indicators consists of 10-19 indicators of a lower degree.

The Reuters Top 100 rating includes the following indicators [14]: Patent citations, Patent citation impact, Percent of patent cited, Patent to article citation impact, Total web of science core 
collection papers, Patent volume, Global patents, Patent success, Industry collaborative articles, Industry article citation impact.

Similar to the Times Higher Education World University Ranking, each of these Reuters Top 100 rating indicators has an overall weight.

Taking into account the main scientific approaches to the interpretation of the University of Entrepreneurship and the identification of its substantive characteristics allowed to form a system of indicators given in Table 1.

Table 1

System of indicators of integrated estimation of educational institutions according to the concept of the entrepreneurial university

\begin{tabular}{|c|c|c|c|}
\hline No. & Name of indicator & Source of information & Weighting factor \\
\hline 1 & International students & Times Higher Education World University Rankings & 0.05 \\
\hline 2 & Teaching & Times Higher Education World University Rankings & 0.15 \\
\hline 3 & International Outlook & Times Higher Education World University Rankings & 0.05 \\
\hline 4 & Total Patents Filed & Reuters Top 100 & 0.05 \\
\hline 5 & Success Rate* & Reuters Top 100 & 0.1 \\
\hline 6 & Commercial Impact Score & Reuters Top 100 & 0.05 \\
\hline 7 & Citation rate & U-Multirank & 0.05 \\
\hline 8 & External research income & U-Multirank & 0.1 \\
\hline 9 & Co-publications with industrial partners & U-Multirank & 0.1 \\
\hline 10 & Income from private sources & U-Multirank & 0.1 \\
\hline 11 & Industry co-patents & U-Multirank & 0.1 \\
\hline 12 & Regional Publications with Industrial Partners & U-Multirank & 0.1 \\
\hline
\end{tabular}

Note: * - ratio of patents filed by the institution that were subsequently granted by patent offices. Source: Made by the author according to the data [13-15]

This system of indicators fully takes into account the concept of the entrepreneurial university and allows to form ratings of educational institutions, to make interpersonal comparisons.

The procedure of standardization of indicators is important, the goal of which is to bring indicators that have different units of measurement to the normalized values.

The calculation of the integrated indicator was made on the basis of the method described by [16].

Verification of the approach proposed by the author was made using data from the Times Higher Education World University Ranking, U-Multirank, Reuters Top 100 ratings.

The results of calculations of the integrated indicator are shown in Fig. 1.

Table 2

Ranking table Top five universities in the world by different ratings

\begin{tabular}{ccc}
\hline $\begin{array}{c}\text { Times Higher Education World Uni- } \\
\text { versity Rankings 2019 }\end{array}$ & $\begin{array}{c}\text { The World's Most Innovative Universi- } \\
\text { ties 2019 (Reurters 100) }\end{array}$ & Rating compiled by the author \\
\hline University of Oxford & Stanford University & Massachusetts Institute of Technology \\
University of Cambridge & Massachusetts Institute of Technology & Stanford University \\
Stanford University & Harvard University & California Institute of Technology \\
Massachusetts Institute of Technology & University of Pennsylvania & University of Oxford \\
California Institute of Technology & University of Washington & University of Cambridge
\end{tabular}

Source: Made by the author according to the data [13, 14, 17]

Data analysis of Fig. 2 and Table 2 testifies to the dominance of US universities. 
That is, the above-mentioned US educational institutions are more in line with the concept of the entrepreneurial university than similar European ones.

The results of a global analysis conducted by Jack Tai [18] showed that 9 of the top 10 schools for venture capital financing were in the United States. As might be expected, Silicon Valley educational institutions have high ratings, as do Ivy League universities. In addition, bachelor programs have created the largest number of venture startups in: Stanford, UC Berkeley, MIT, Harvard, University of Pennsylvania, Cornell, University of Michigan, Tel Aviv University, University of Texas and University of Illinois [18].

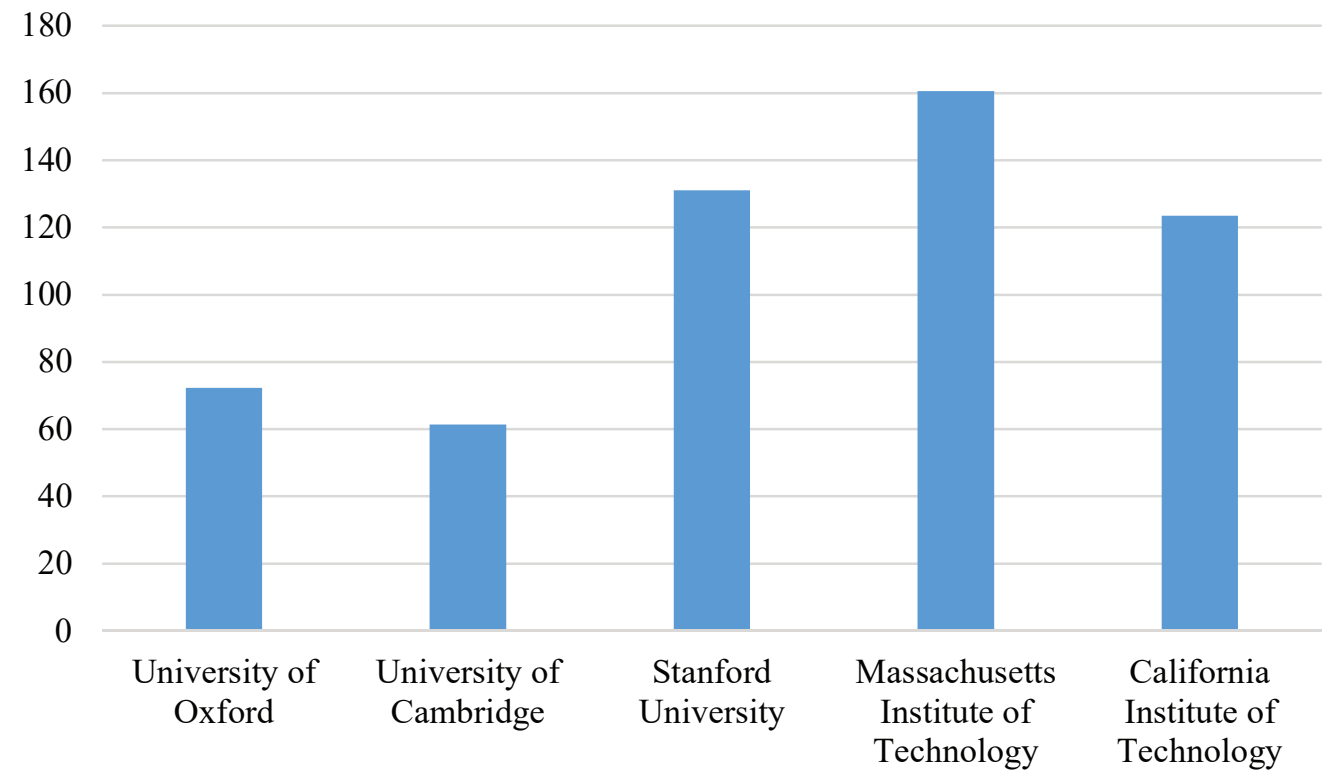

Fig. 1. Integral indicator of activity of separate educational institutions according to the concept of business university. Source: Made by the author

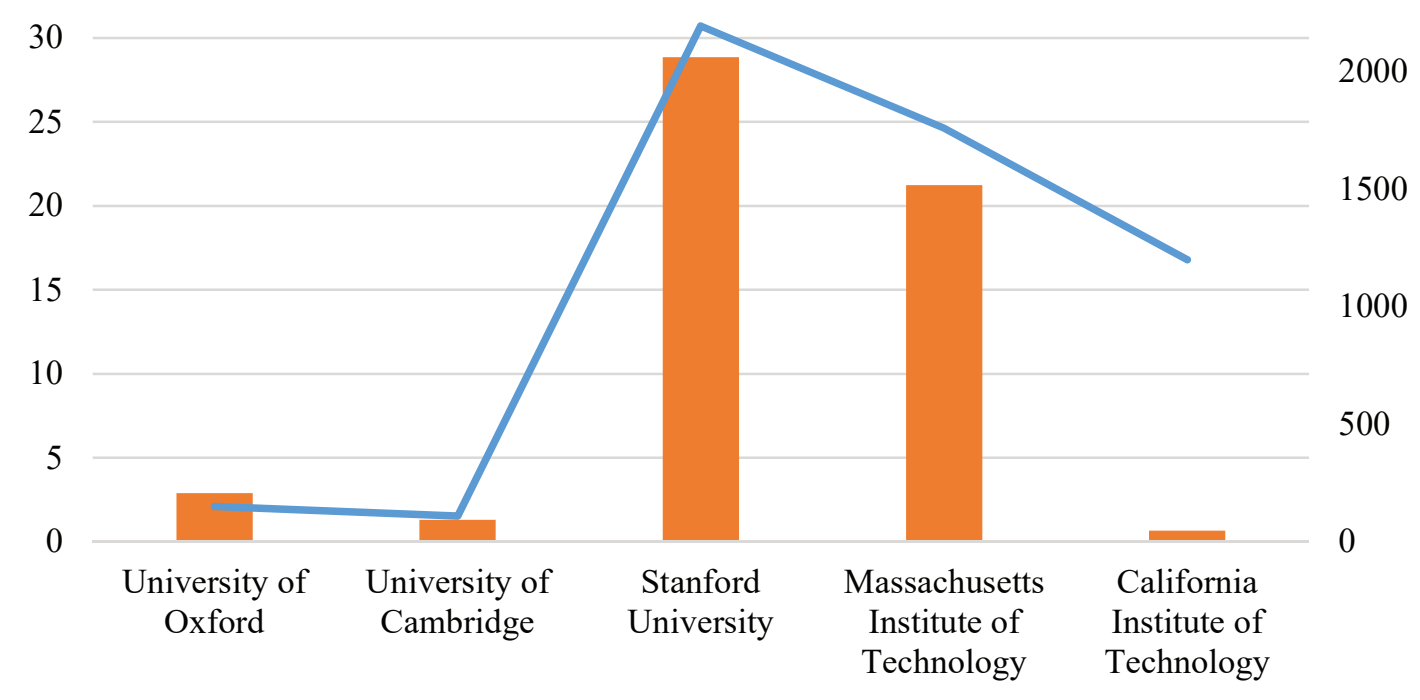

Capital raised, billion USD Entrepreneurs \& Companies, units (right scale)

Fig. 2. University comparison. Source: Made by the author according to the data [19]

The limitations in the article are that the scientific approach has been tested at five universities. The rating formed using data from more educational institutions may look different. Prospects 
for further research may be the approbation of the proposed scientific approach in a larger sample of educational institutions.

\section{Conclusions}

The article describes two main approaches to estimating the activity of institutions from the standpoint of the concept of the entrepreneurial university. The author analyzes the advantages and disadvantages of each viewpoint. It is substantiated that the combined approach is more flexible and allows to form a system of indicators of estimation of mentioned universities, which takes into account the peculiarities of this concept. The results show that of the five universities surveyed, three represent the United States. In particular, the calculated integrated indicator for the Massachusetts Institute of Technology is 160.5; for Stanford University it is 131.1; for California Institute of Technology - 123.5. In this case, the value of the integrated indicator for the University of Oxford is 72.3; for the University of Cambridge -61.3 .

A study of the available information indicates that US universities are more successful in raising funds and commercializing research results. For example, the results of a comparative analysis of the studied educational institutions showed that Stanford University (USA) attracted 9.9 times more funds than the University of Oxford (UK).

At the same time, indicators of the impact on regional socio-economic development have, in fact, similar values of the studied institutions in the United States and Europe.

\section{References}

[1] Meissner, D., Erdil, E., Chataway, J. (Eds.) (2018). Innovation and the Entrepreneurial University. Springer, 327. doi: http://doi. org/10.1007/978-3-319-62649-9

[2] Landinez L., Kliewe T., Diriba H.; Kliewe, T., Kesting, T., Plewa, C., Baaken, T. (Eds.) (2019). Entrepreneurial University Indicators in Global University Rankings. Developing Engaged and Entrepreneurial Universities. Singapore: Springer, 57-85. doi: http://doi.org/10.1007/978-981-13-8130-0_4

[3] Guerrero, M., Cunningham, J. A., Urbano, D. (2015). Economic impact of entrepreneurial universities' activities: An exploratory study of the United Kingdom. Research Policy, 44 (3), 748-764. doi: http://doi.org/10.1016/j.respol.2014.10.008

[4] Mammadli, A. (2021). Global University Rating Indicators and Suggestion for Establishment of Entrepreneur Universities in Azerbaijan. InterConf, 192-210. doi: http://doi.org/10.51582/interconf.19-20.02.2021.016

[5] Kurmaiev, P. Yu., Pyzhianova, N. V. (2017). Organizational and economic mechanism of state regulation of higher education system in Ukraine. Scientific Bulletin of Polissya, 1 (1 (9)), 107-112. doi: http://doi.org/10.25140/2410-95762017-1-1(9)-107-112

[6] Sperrer, M., Müller, C., Soos, J. (2016). The Concept of the Entrepreneurial University Applied to Universities of Technology in Austria: Already Reality or a Vision of the Future? Technology Innovation Management Review, 6 (10), 37-44. doi: http:// doi.org/10.22215/timreview/1026

[7] 2019 University Entrepreneurship Index (2021). ILLINOIS SCIENCE \& TECHNOLOGY COALITION. Available at: https://www.istcoalition.org/data/index/2019-university-entrepreneurship-index Last accessed: 05.10.2021

[8] Etzkowitz, H. (2017). Innovation Lodestar: The entrepreneurial university in a stellar knowledge firmament. Technological Forecasting and Social Change, 123, 122-129. doi: http://doi.org/10.1016/j.techfore.2016.04.026

[9] Wissema, J. G. (2009). Towards the third generation university: Managing the university in transition. Cheltenham: Edward Elgar Publishing. doi: http://doi.org/10.4337/9781848446182

[10] Guerrero, M., Urbano, D. (2010). The development of an entrepreneurial university. The Journal of Technology Transfer, 37 (1), 43-74. doi: http://doi.org/10.1007/s10961-010-9171-x

[11] Fernández-Nogueira, D., Arruti, A., Markuerkiaga, L., Saenz, N. (2018). The entrepreneurial university: A selection of good practices. Journal of Entrepreneurship Education, 2 1(3), 1-17.

[12] Polishchuk, E. V. (2012). Requirements for the Indicator System Efficiency of the Enterprise. Proceedings of Voronezh State University. Series: Economics and Management, 2, 182-189

[13] The World University Ranking (2019). The Times Higher Education World University Ranking 2019. Available at: https:// www.timeshighereducation.com/world-university-rankings/2019/world-ranking\#!/page/0/length/25/sort_by/rank/sort_order/ asc/cols/stats Last accessed: 07.10.2021

[14] Ewalt, D. (2019). The World's Most Innovative Universities - 2019. Available at: https://www.reuters.com/innovative-universities-2019 Last accessed: 07.10.2021

[15] University comparison (2019). U-Multirank. Available at: https:/www.umultirank.org/compare?trackType=compare\&sightMode= undefined\&section $=$ compareRanking\&mode=likewithlike\&instutionalField=true \&pref-4=1\&pref-4=2\&name=null 
$\&$ country $=7 \&$ country $=52 \&$ country $=58 \&$ country $=63 \&$ country $=45 \&$ sortOrder $=$ desc $\&$ sortCol $=$ overallPerformance Last accessed: 05.10.2021

[16] Erastov, A. E., Novikova, O. V. (2015). Method of calculation of the integral index of effective realization of regional energy efficiency programs. Vestnik IGEU, 3, 73-80. doi: http://doi.org/10.17588/2072-2672.2015.3.073-080

[17] Garafonova, O. I., Kurmaiev, P. Y. (2018). Percularties of management mechanism formation by means of changes as the basis of strategic development of business organizations. Scientific Bulletin of Polissia, 3 (15), 7-11. doi: http://doi.org/10.25140/24109576-2018-3(15)-7-11

[18] Tai, J. (2020). Which Colleges Produce The Most Startups? Available at: https://www.forbes.com/sites/theyec/2020/06/09/ which-colleges-produce-the-most-startups/?sh=7652a9c71ad8 Last accessed: 05.10.2021

[19] Gabbert, J. (Ed.) (2019). Pitchbook Universities: 2018-2019 Edition. Seattle: PitchBook Data, Inc. 